\title{
Effects of Acupuncture on Heart Rate Variability in Obese Premenopausal Korean Women
}

\author{
Yo-Chan Yang ${ }^{1}$, Je-In Kim ${ }^{1}$, Koh-Woon Kim¹, Jae-Heung Cho ${ }^{1}$, Song-Yi Kim², \\ Hi-Joon Park ${ }^{2}$, Mi-YeonSong ${ }^{1}$ \\ ${ }^{1}$ Dept. of Korean Rehabilitation Medicine, College of Korean Medicine, Kyung Hee University \\ ${ }^{2}$ Studies of Translational Acupuncture Research, Acupuncture and Meridian Science Research Center, \\ Kyung Hee University
}

\begin{abstract}
Objectives: Although the autonomic nervous system (ANS) is thought to play an important role in treatment of obesity, no study has been conducted to investigate acupuncture's effects on this aspect of the ANS. This study aimed to describe the effects of acupuncture in the ANS by means of heart rate variability (HRV) analysis.

Methods: A total of 46 obese women aged from 21 to 54 with body mass index ranging from 25.1 to $39.3 \mathrm{~kg} / \mathrm{m}^{2}$ were recruited and randomized into both the real acupuncture group $(n=23)$ and sham acupuncture group $(n=23)$. A total of 3 instances of HRV analysis were conducted before, during, and after treatment. Statistically significant differences between time and groups were analyzed using repeated measure analysis of variance.

Results: All parameters of time domain analysis and frequency domain analysis except for the square root of the mean squared differences of successive normal sinus intervals (RMSSD) and very low frequency (VLF) showed significant differences between times. The mean of all R-R intervals (mean RR) showed significant level of interaction between time and group. Between groups, time domain analysis of standard deviation of the normal-to-normal intervals (SDNN), RMSSD and frequency domain analysis of total power (TP) and high frequency (HF) showed significant differences.

Conclusions: The real acupuncture group showed deactivation of parasympathetic function and relative increase of sympathetic activity in obese subjects. Further studies are necessary to uncover the mechanisms of acupuncture in obesity treatment.
\end{abstract}

$\overline{\text { Key Words }}$ : Obesity, acupuncture, autonomic nervous system, heart rate variability

\section{Introduction}

Heart rate variability (HRV) refers to beat-to-beat fluctuations in the rhythm of the heart, or the way in which the time intervals between heart beats change over time $^{1)}$. This variation results from the regulation of the sinoatrial node of the heart by the sympathetic and parasympathetic branches of the autonomic nervous system (ANS). HRV therefore reflects the activity of the ANS and is a reliable, useful, and non-invasive means to provide a comprehensive, quantitative, and qualitative evaluation of neuroautonomic function $^{2)}$. Various studies utilize this tool for researching physiological mechanisms of the body and predicting mortality of certain patient populations such as myocardiac infarction patients ${ }^{3}$.

Numerous studies have investigated the impact of acupuncture on HRV in both humans and animals. A

\footnotetext{
- Received : 23 October 2014 - Revised : 19 November 2014 Accepted : 21 November 2014

- Correspondence to : Mi-Yeon Song

Dept. of Korean Rehabilitation Medicine, College of Korean Medicine, Kyung Hee University,

Hoegi-dong, Dongdaemun-gu, Seoul, Korea, 130-701

Tel : +82-2-440-7580, Fax : +82-2-440-6854, Email : mysong@khu.ac.kr
} 
systematic review of human studies ${ }^{4)}$ was published in 2010 and this study included 12 randomized controlled trials (RCTs) which compared acupuncture to a sham (placebo) acupuncture intervention. A recent study $^{5)}$ added four more RCTs to these 12 studies and revealed that only 4 of 16 RCTs studied subjects with medically diagnosed conditions (depression and anxiety, migraine headaches, post stroke insomnia, and congestive heart failure). The rest of the RCTs studied healthy subjects in their normal baseline state or under certain conditions of artificially induced stress. RCTs for the effects of acupuncture on HRV in obese subjects have never been conducted.

Considering the autonomic nervous system plays an important role in the regulation of energy expenditure and body fat storage ${ }^{6,7)}$, the utilization of HRV measurements in studies concerning obesity is plausible. Several studies which used HRV in obese subjects have shown that regional body fat distribution is related to HRV indices ${ }^{8)}$ and weight loss increased parasympathetic control of $\mathrm{HRV}^{9}$. Acupuncture has been applied extensively around the world as an alternative treatment to reduce body weight ${ }^{10)}$. The underlying mechanisms of acupuncture in weight reduction might result from reducing appetite $^{11)}$ and splitting fat ${ }^{12)}$, but regulating the activity of ANS could also be a possible mechanism.

The purpose of this study was to evaluate the effects of acupuncture on HRV in obese premenopausal Korean women.

\section{Methods}

\section{Subjects}

This was a prospective study conducted from 4 April to 16 May, 2014. All study procedures were approved by the Institutional Review Board (IRB) of Kyung Hee University Hospital at Gang-dong (IRB file No.: 2013-01-020). Subjects were recruited through newspaper advertisements and announcements on the hospital's noticeboard. To minimize hormonal effects $^{13)}$, obese Korean women between 18 and 55 years of age who were in premenopausal state were enrolled in this study. A total of 50 subjects accepted the allocation and gave written informed consent. All subjects met the following inclusion criteria: (i) $>25 \mathrm{~kg} / \mathrm{m}^{2}$ body-mass index (BMI), (ii) 18 to 55 years of age, (iii) in premenopausal state with regular menstruation. Individuals with the following conditions were excluded: (i) gynecological disease including hysterectomy and/or oophorectomy, (ii) cardiac arrhythmia or an implanted cardiac pacemaker, (iii) history of taking medication including female hormones, thyroid hormones, oral steroids, or antihypertensives in the 3 months preceding the study, (iv) pregnant or lactating state.

\section{Groups and intervention}

The subjects were randomly assigned to either the real acupuncture group (RA) or sham acupuncture group (SA) in a 1:1 ratio using a random number generator (Excel, Microsoft Corp., Redmond, WA, USA).

This study was composed of one treatment session. The intervention was delivered in the outpatient department at the Wellness Center of Kyung Hee University Hospital at Gang-dong. Each subject received the intervention in an individual room and lay on a bed throughout the process.

The intervention combined manual acupuncture and electroacupuncture. Considering the fact that electroacupuncture is widely used to treat obese patients in many clinics, we decided to set intervention including electroacupuncture. In addition to electroacupuncture, we set manual acupuncture to promote the effects and chose acupuncture points based on traditional acupuncture theory.

The acupuncture treatment comprised a total of 30 minutes session in both groups. As clinical settings 
for electroacupuncture treatments in obese patients, 25 minutes of "lypolytic phase" with $25 \mathrm{~Hz}$ electrical stimulation followed by 5 minutes of "elasticity maintenance phase" with $60 \mathrm{~Hz}$ electrical stimulation comprised the 30-minute session. The acupuncture points were chosen in accordance with the theories of traditional Korean medicine and followed the World Health Organization Standard Acupuncture Point Locations ${ }^{14)}$. For the RA group, 10 acupuncture needles (Dongbangacupuncture, $0.25 \mathrm{X} 40 \mathrm{~mm}$ ) were inserted vertically in Zhongwan (CV12, middle), Qihai (CV6, middle), Hegu (LI4, bilateral), Quchi (LI11, bilateral), Zusanli (ST36, bilateral), and Sanyinjiao (SP6, bilateral). For the purpose of patient blinding, Park tube designed for Park's sham needle $^{15)}$ was attached to these 10 acupuncture points before inserting needles. Additionally, four long needles (Dongbangacupuncture, $0.25 \times 75 \mathrm{~mm}$ ) were inserted obliquely in Tianshu (ST25, bilateral) and Shuidao (ST28, bilateral). Electrical stimulation was applied to these 4 acupuncture points in which long needles were inserted.

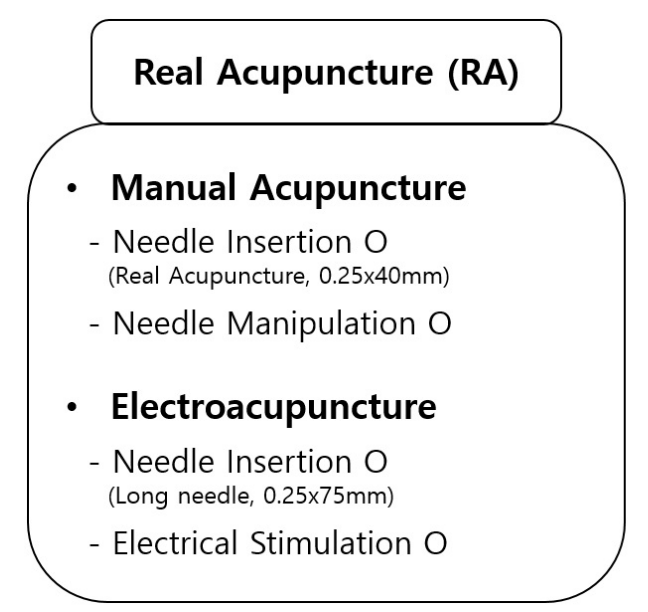

In the SA group, Park's sham needle ${ }^{15)}$ was administered for each subject. Sham acupuncture

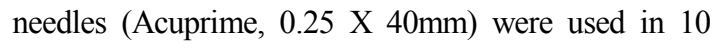
Park tube-attached acupuncture points. The tips of the sham needles were blunt, so that these needles were not inserted intradermally but just held in place by Park tubes. Insertion of 4 long needles was conducted same as with the RA group, but the leads to these 4 needles were connected to an inactive channel of the electrical stimulator. The stimulator was turned on, but electrical pulses were delivered to an unconnected channel. In contrast, the RA group received real electrical pulses through the long needles. However, the intensity of pulses was set under the detection threshold so that subjects of the RA group also couldn't sense the electrical stimulation.

In both groups, needle manipulation (twisting and pressuring) for enhancing the acupuncture sensation (called de $q i$ in Korean medicine) was performed with inserting needles. All subjects were told that they would receive real acupuncture treatment with

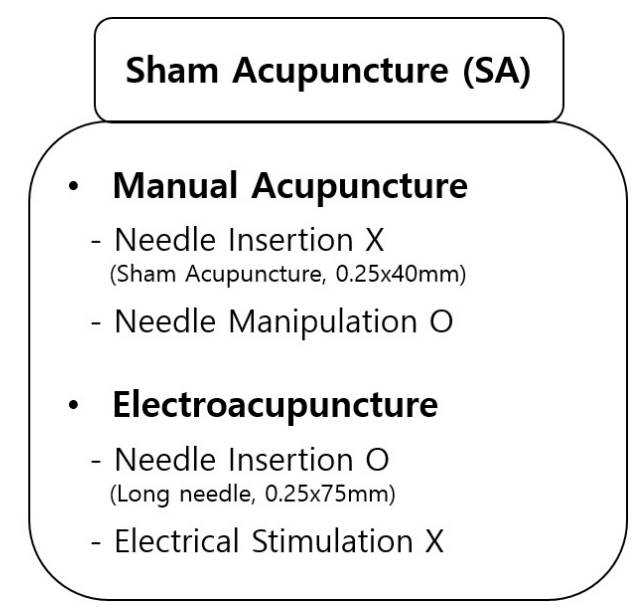

Fig. 1. Groups and intervention.

Both groups received the intervention of manual acupuncture and electroacupuncture. In manual acupuncture, while the real acupuncture (RA) group was treated with real acupuncture needle insertion, the sham acupuncture (SA) group was not. In electroacupuncture, RA received electrical stimulation through the needles inserted, and $S A$ received actual needle insertion without electrical stimulation. 
real electrical stimulation which can't be felt due to low intensity, so that subject blinding was achieved. Comparison of both groups' intervention is summarized in Figure 1.

\section{HRV measurement}

HRV was recorded in a supine position after a 5-minutes rest and in a quiet room at room temperature using the Heart Rhythm Scanner (Version 2.0, Biocomtechnologies, Washington, USA). In this study, 5 minutes of data were recorded to analyze the short-term effect of heart and pulse rates. Three leads of HRV were attached, $4 \mathrm{~cm}$ above the right nipple, $4 \mathrm{~cm}$ below the left nipple, and on the lateral left side. The subjects were earlier told to avoid alcohol, coffee, and cigarettes within $12 \mathrm{~h}$ and any kinds of food ingestion within $1 \mathrm{~h}$ before the measurement. The experimental sequence is shown in Figure 2. HRV was measured 3 times during the experiment; 5 minutes before acupuncture treatment, 5 minutes after electrical pulses started, and 5 minutes after the removal of acupuncture. All HRV data were collected between 9 am and $1 \mathrm{pm}$.

The time domain analysis of HRV included the heart rate (HR), the mean of all R-R intervals (mean $R R$ ), the standard deviation of all R-R intervals $(\mathrm{SDNN})$, and the square root of the mean squared differences of successive normal sinus intervals (RMSSD). SDNN was considered to reflect overall
HRV (like TP), whereas RMSSD was considered to be an index of parasympathetic modulations of heart rate $^{16)}$. The frequency domain analysis included the total power (TP), the very low frequency (VLF: $\leq$ $0.04 \mathrm{~Hz}$ ), the low frequency (LF: $0.04-0.15 \mathrm{~Hz}$ ), and the high frequency (HF: $0.15-0.4 \mathrm{~Hz}$ ) spectral components. The LF domain reflects both the sympathetic and the parasympathetic nervous systems and the HF domain primarily reflects vagal cardiac control (like RMSSD) ${ }^{16}$. The LFnu and HFnu represented the relative value of the LF or HF power in proportion to the total power minus the VLF power. The $\mathrm{LF} / \mathrm{HF}$ ratio, considered to reflect sympatho-vagal balance, ${ }^{16)}$ was calculated.

\section{Data analysis}

All values are expressed as mean \pm standard deviation (SD). Student's t-test was used to test for differences between the two groups at baseline. Repeated measure analysis of variance (ANOVA) was performed to compare the before/during/after changes in HRV indices for both the RA and SA groups. All analyses were conducted by Statistical Package for the Social Sciences (SPSS) version 16.0 program for Windows. A p-value less than 0.05 was considered statistically significant.

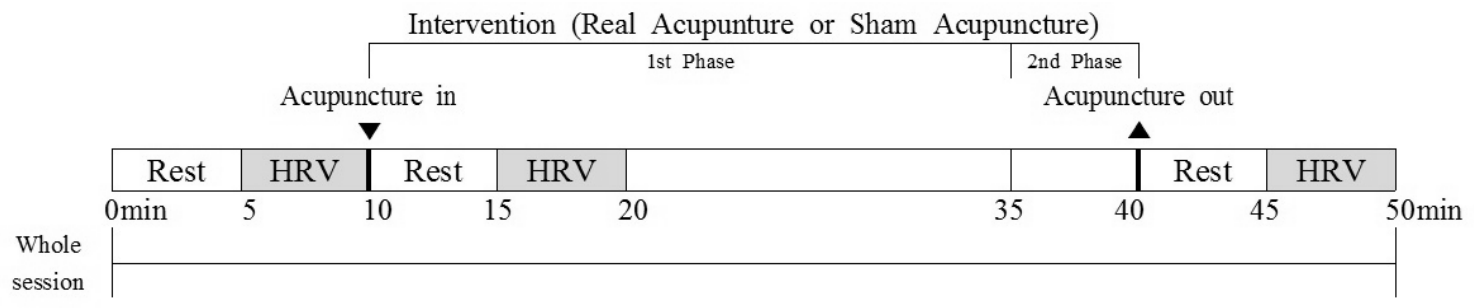

Fig. 2. The experimental sequence.

Heart rate variability (HRV) was measured 3 times during whole session; 5 minutes before acupuncture treatment, 5 minutes after electrical pulses started, and 5 minutes after the removal of acupuncture. Each measurement was preceded by 5 minutes of rest. 
(444) Journal of Korean Medicine 2014;35(4)

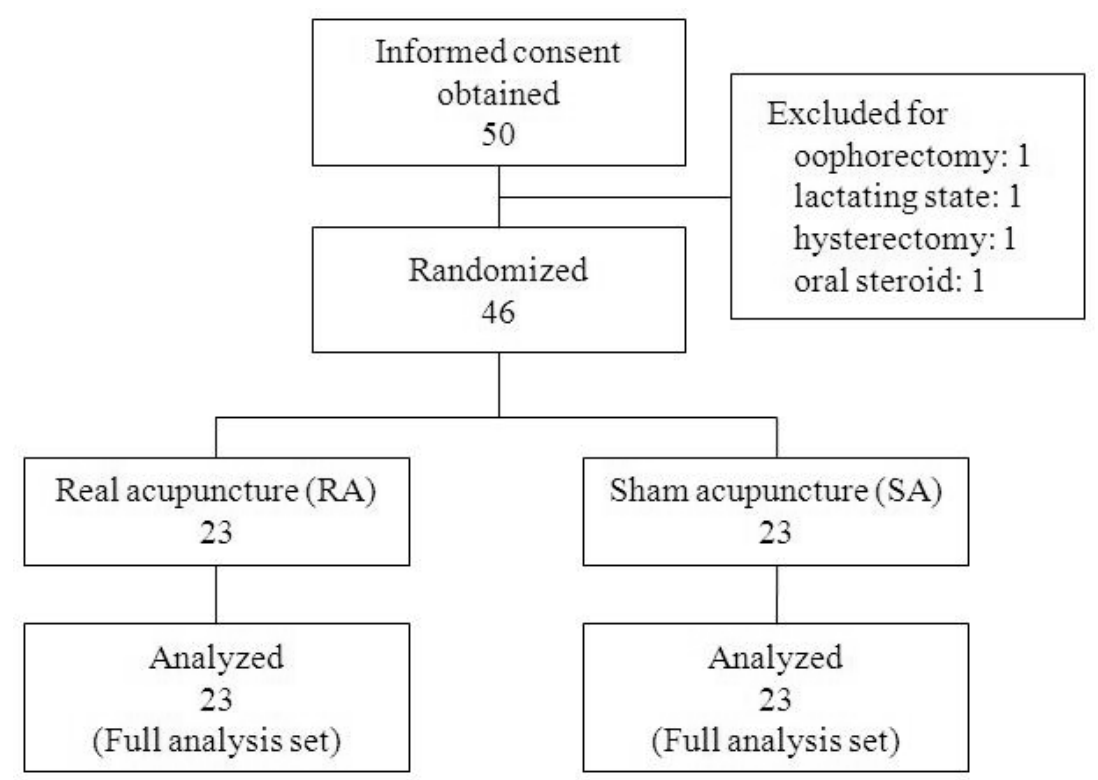

Fig. 3. Flow chart of the study.

50 applicants provided written informed consent. 4 of 50 subjects were excluded by exclusion criteria, resulting in a sample population of 46 subjects. 46 subjects were randomly assigned to either the real acupuncture (RA) group or the sham acupuncture (SA) group in a 1:1 ratio, and results of 46 subjects were analyzed.

Table 1. Subjects' General Characteristics and Baseline Data of Heart Rate Variability $(n=46)$

\begin{tabular}{|c|c|c|c|}
\hline & $\begin{array}{c}\mathrm{RA} \\
(\mathrm{n}=23)\end{array}$ & $\begin{array}{c}\text { SA } \\
(n=23)\end{array}$ & p-value \\
\hline Age (years) & $35.74 \pm 9.44$ & $37.57 \pm 7.15$ & .463 \\
\hline Height $(\mathrm{cm})$ & $163.06 \pm 5.09$ & $160.11 \pm 6.15$ & .085 \\
\hline Weight (kg) & $78.39 \pm 9.39$ & $75.13 \pm 11.14$ & .290 \\
\hline BMI $\left(\mathrm{kg} / \mathrm{m}^{2}\right)$ & $29.52 \pm 3.64$ & $29.26 \pm 3.53$ & .808 \\
\hline HR (bpm) & $69.49 \pm 8.32$ & $67.38 \pm 9.51$ & .427 \\
\hline Mean RR (ms) & $874.79 \pm 100.00$ & $905.05 \pm 109.83$ & .334 \\
\hline SDNN (ms) & $36.04 \pm 11.99$ & $43.36 \pm 16.99$ & .098 \\
\hline RMSSD (ms) & $25.03 \pm 11.18$ & $34.16 \pm 19.80$ & .061 \\
\hline $\mathrm{TP}\left(\mathrm{ms}^{2}\right)$ & $473.90 \pm 343.13$ & $690.05 \pm 730.35$ & .208 \\
\hline $\operatorname{VLF}\left(\mathrm{ms}^{2}\right)$ & $290.40 \pm 273.73$ & $376.82 \pm 483.98$ & .460 \\
\hline $\mathrm{LF}\left(\mathrm{ms}^{2}\right)$ & $124.39 \pm 100.54$ & $194.48 \pm 209.11$ & .157 \\
\hline $\mathrm{HF}\left(\mathrm{ms}^{2}\right)$ & $59.12 \pm 52.72$ & $110.96 \pm 115.43$ & .059 \\
\hline LFnu $(\%)$ & $67.73 \pm 16.39$ & $62.65 \pm 21.28$ & .369 \\
\hline HFnu(\%) & $32.27 \pm 16.39$ & $37.35 \pm 21.28$ & .369 \\
\hline $\mathrm{LF} / \mathrm{HF}$ & $3.79 \pm 4.84$ & $3.35 \pm 4.19$ & .744 \\
\hline
\end{tabular}

Values are mean \pm standard deviation

RA: real acupuncture

SA: sham acupuncture 


\section{Results}

\section{General characteristics of subjects}

50 applicants provided written informed consent; 4 of them were excluded based on exclusion criteria (1 for history of hysterectomy, 1 for history of oophorectomy, 1 for lactating state, 1 for history of taking oral steroids), resulting in a sample population of 46 subjects (Fig. 3). The 46 subjects were aged from 21 to 54 years and had a BMI range of 25.1 to $39.3 \mathrm{~kg} / \mathrm{m}^{2}$. All included subjects were randomly assigned to either the RA group $(n=23)$ or the SA group ( $n=23)$. Subjects' demographics, anthropometric data, and baseline data of HRV are summarized based on groups in Table 1. There were no statistically significant differences between the groups.

\section{Changes of HRV parameters during the whole session}

All parameters of time domain analysis and frequency domain analysis except for RMSSD and
VLF showed significant differences between times. Mean RR showed significant level of interaction between time and group $(\mathrm{p}=0.035)$, but the rest of the parameters had no significant interaction between time and group. Between groups, time domain analysis of SDNN, RMSSD and frequency domain analysis of TP, HF showed significant differences (SDNN for $\mathrm{p}=0.039$, RMSSD for $\mathrm{p}=0.035$, TP for $\mathrm{p}=0.030$, HF for $\mathrm{p}=0.047$ ) (Table 2). Compared to $\mathrm{SA}, \mathrm{RA}$ showed the effects of relative decrease in RMSSD, HF, SDNN, and TP (Fig.4-5).

\section{Discussion}

The ANS directs voluntary and involuntary physiologic processes such as digestion, blood pressure, hormonal regulation, energy metabolism, and heart rate and is therefore considered an important regulator of homeostasis ${ }^{17}{ }^{18)}$. $\mathrm{HRV}$ is widely used in various studies for measuring and evaluating the ANS. However, several variables that can affect HRV make it difficult to draw a firm

Table 2. The Changes of Heart Rate Variability Indices (Time Domain Analysis)

\begin{tabular}{|c|c|c|c|c|c|}
\hline HRV & Group & $\begin{array}{c}\text { Before } \\
\text { Treatment }\end{array}$ & $\begin{array}{c}\text { During } \\
\text { Treatment }\end{array}$ & $\begin{array}{c}\text { After } \\
\text { Treatment }\end{array}$ & $\mathrm{p}$-value \\
\hline $\begin{array}{c}\text { HR } \\
(\mathrm{bpm})\end{array}$ & $\begin{array}{l}\text { RA } \\
\text { SA }\end{array}$ & $\begin{array}{l}69.49 \pm 8.32 \\
67.38 \pm 9.51\end{array}$ & $\begin{array}{l}67.45 \pm 8.55 \# \\
64.91 \pm 7.11 \#\end{array}$ & $\begin{array}{c}68.80 \pm 7.86 \\
64.55 \pm 7.81 \#\end{array}$ & $\begin{array}{c}\text { Time } .000 * * \\
\text { Time } \times \text { Group.069 } \\
\text { Group } .216\end{array}$ \\
\hline $\begin{array}{l}\text { Mean RR } \\
\quad(\mathrm{ms})\end{array}$ & $\begin{array}{l}\text { RA } \\
\text { SA }\end{array}$ & $\begin{array}{l}874.79 \pm 100.00 \\
905.05 \pm 109.83\end{array}$ & $\begin{array}{c}902.84 \pm 110.54 \# \\
934.04 \pm 94.60 \#\end{array}$ & $\begin{array}{c}882.58 \pm 96.77 \$ \\
942.30 \pm 112.33 \#\end{array}$ & $\begin{array}{c}\text { Time.000** } \\
\text { Time } \times \text { Group.035* } \\
\text { Group. } 183\end{array}$ \\
\hline $\begin{array}{l}\text { SDNN } \\
(\mathrm{ms})\end{array}$ & $\begin{array}{l}\text { RA } \\
\text { SA }\end{array}$ & $\begin{array}{l}36.04 \pm 11.99 \\
43.36 \pm 16.99\end{array}$ & $\begin{array}{l}36.24 \pm 10.43 \\
45.10 \pm 20.25\end{array}$ & $\begin{array}{l}41.94 \pm 13.00 \#, \$ \\
54.49 \pm 25.30 \#, \$\end{array}$ & $\begin{array}{c}\text { Time.000** } \\
\text { Time } \times \text { Group.411 } \\
\text { Group.039* }\end{array}$ \\
\hline $\begin{array}{l}\text { RMSSD } \\
\quad(\mathrm{ms})\end{array}$ & $\begin{array}{l}\text { RA } \\
\text { SA }\end{array}$ & $\begin{array}{l}25.03 \pm 11.18 \\
34.16 \pm 19.80\end{array}$ & $\begin{array}{l}27.54 \pm 11.58 \\
38.47 \pm 27.73\end{array}$ & $\begin{array}{l}24.56 \pm 10.44 \\
39.56 \pm 25.46\end{array}$ & $\begin{array}{c}\text { Time.053 } \\
\text { Time } \times \text { Group. } 110 \\
\text { Group. } 035^{*}\end{array}$ \\
\hline
\end{tabular}

\footnotetext{
Values are mean \pm standard deviation

\#: significantly different from before-treatment by paired t-test

$\$$ : significantly different from during-treatment by paired t-test

*: significant at $\mathrm{p}<0.05$ by repeated measure ANOVA

**: significant at $\mathrm{p}<0.01$ by repeated measure ANOVA

RA: real acupuncture

SA: sham acupuncture
} 


\section{(a) RMS SD}

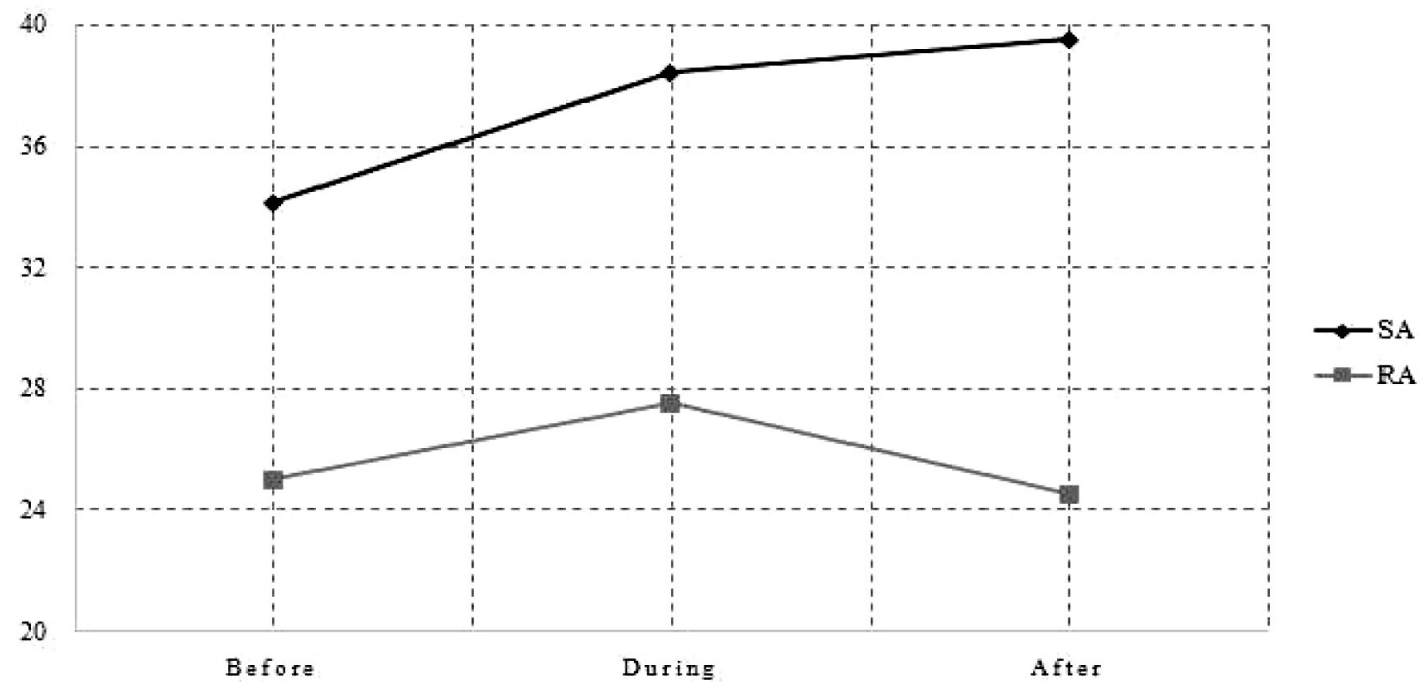

(b) $\mathrm{HF}$

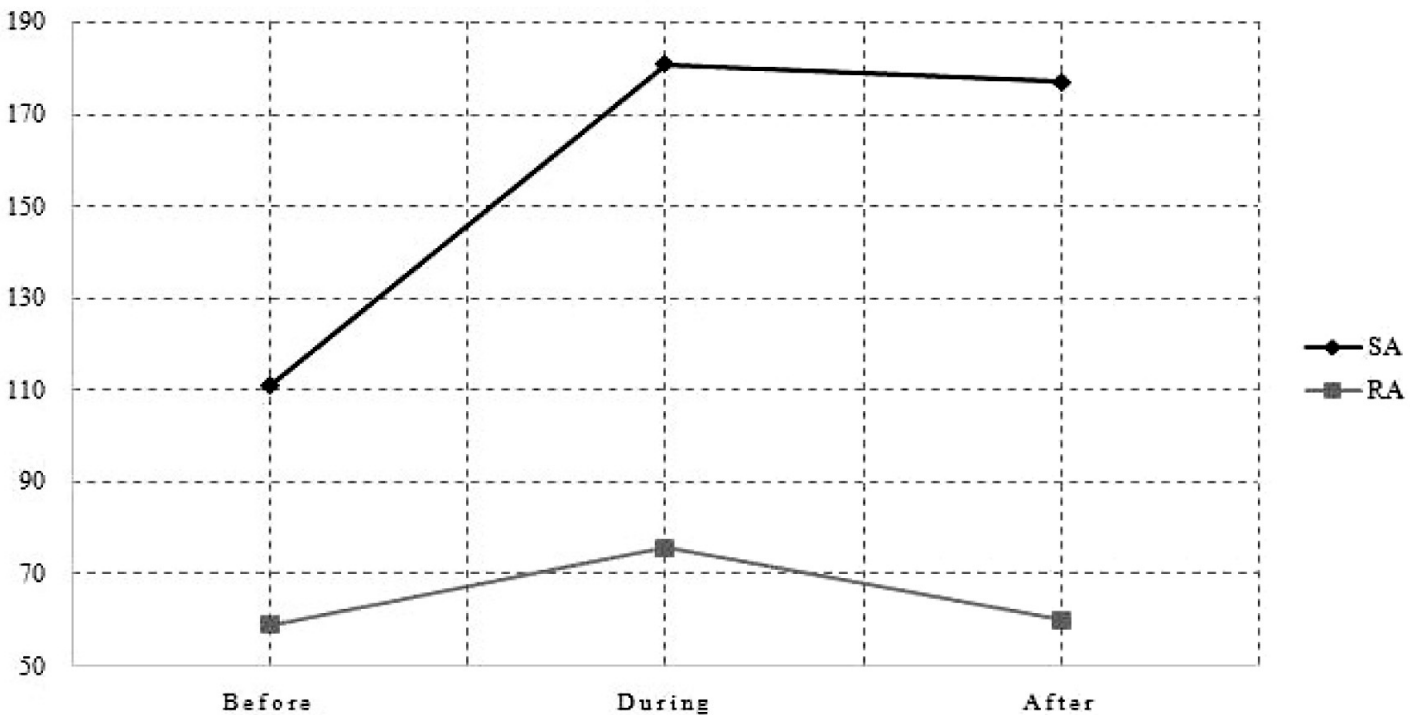

Fig. 4. The change patterns of RMSSD and HF parameters.

Both the real acupuncture (RA) and the sham acupuncture (SA) groups showed no significant differences between 3 measurements in RMSSD. RA showed a significant decrease at after-treatment measurement compared to during-treatment measurement in HF $(p=0.023)$. 
(a) SDNN

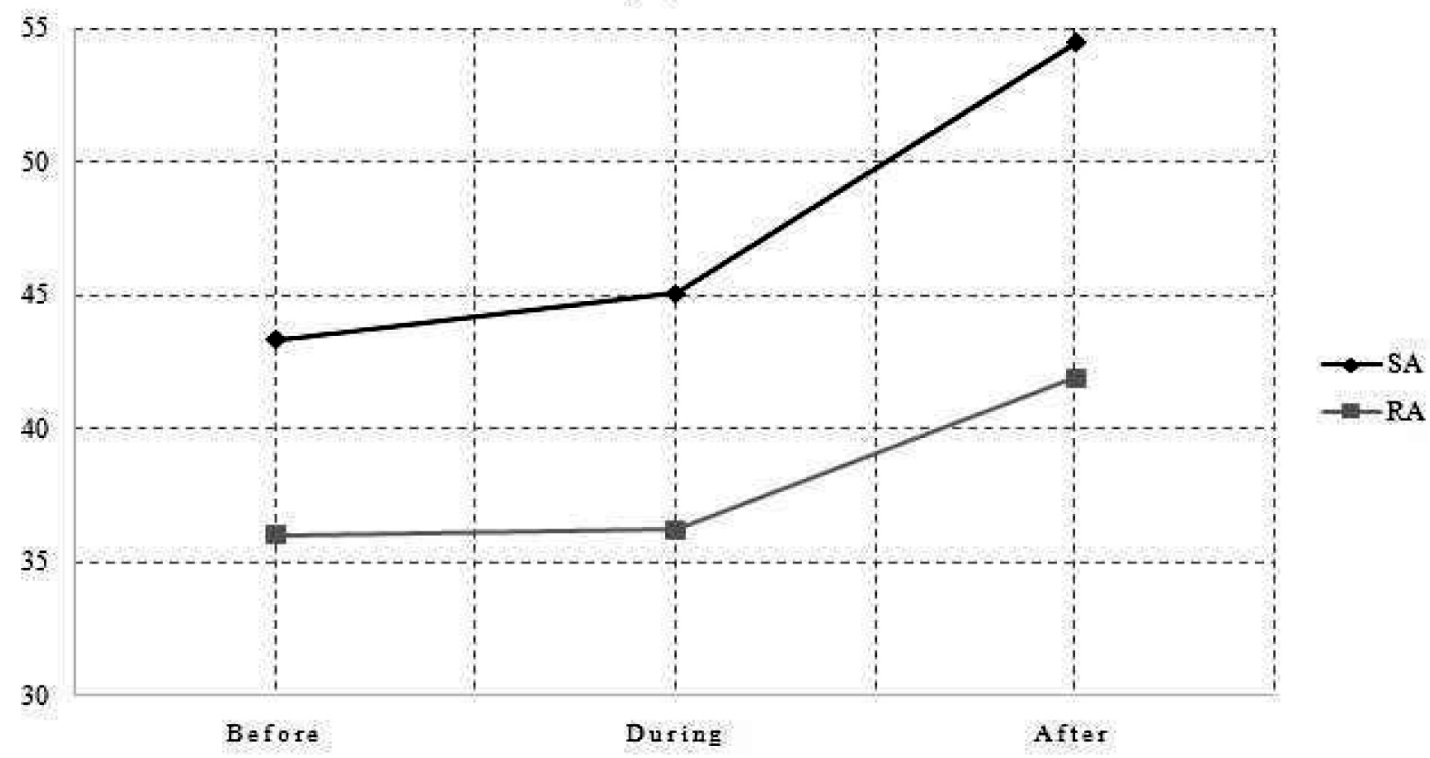

(b) $\mathbf{T} \mathbf{P}$

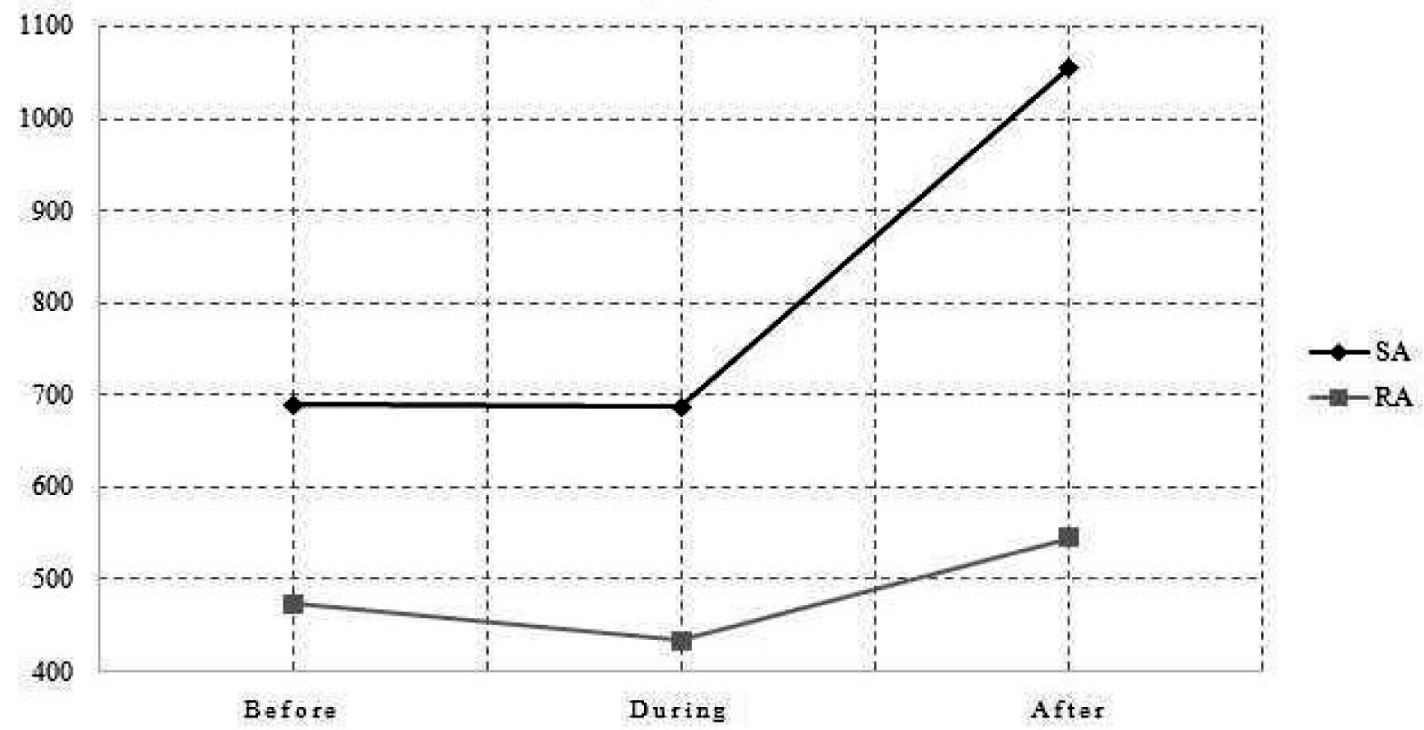

Fig. 5. The change patterns of SDNN and TP parameters.

Both the real acupuncture (RA) and the sham acupuncture (SA) groups showed no significant differences between 3 measurements in TP. Both groups showed a significant increase at after-treatment measurement compared to previous 2 measurements in SDNN. 
conclusion about the ANS. Strict control of these variables like caffeine intake, smoking, subject's position, must preceded HRV measurement.

Most RCTs using HRV were performed on healthy subjects ${ }^{5}$. Considering the fact that acupuncture has balancing mechanisms, healthy subjects with normal functions cannot show clear effects of acupuncture on $\mathrm{HRV}^{19)}$. Therefore, HRV research about obesity is better to choose obese subjects to conduct RCTs.

Windham et $\mathrm{al}^{8}{ }^{8}$ revealed that increasing waist circumference was associated with decreasing SDNN and RMSSD. The correlation between central obesity and HRV means that electroacupuncture can possibly affect the ANS. In previous studies conducted with obese women $^{20,21)}$, electroacupuncture treatment was shown to be effective in decreasing waist circumference, which is the most affected variable among obesity related variables.

There were no RCTs studying how acupuncture affects HRV in obese subjects. Chien et al. ${ }^{22)}$ used the intervention of transcutaneous electrical stimulation of acupoints, not acupuncture needling, and observed the changes of HRV in postmenopausal women. 12 weeks of treatment showed improvements in waist circumference and weight. They, however, couldn't find any significant changes of HRV after 12 weeks' treatment. They concluded that electrical stimulation of acupoints had a local effect of adipose tissue lipolysis on the abdominal fat. Further study

Table 3. The Changes of Heart Rate Variability Indices (Frequency Domain Analysis)

\begin{tabular}{|c|c|c|c|c|c|}
\hline HRV & Group & $\begin{array}{c}\text { Before } \\
\text { Treatment }\end{array}$ & $\begin{array}{c}\text { During } \\
\text { Treatment }\end{array}$ & $\begin{array}{c}\text { After } \\
\text { Treatment }\end{array}$ & p-value \\
\hline $\mathrm{TP}(\mathrm{ms} 2)$ & $\begin{array}{l}\text { RA } \\
\text { SA }\end{array}$ & $\begin{array}{l}473.90 \pm 343.13 \\
690.05 \pm 730.35\end{array}$ & $\begin{array}{l}433.95 \pm 224.14 \\
687.74 \pm 566.02\end{array}$ & $\begin{array}{c}545.31 \pm 313.82 \\
1056.55 \pm 1069.48\end{array}$ & $\begin{array}{c}\text { Time.023* } \\
\text { Time } \times \text { Group. } 230 \\
\text { Group.030* }\end{array}$ \\
\hline $\operatorname{VLF}(\mathrm{ms} 2)$ & $\begin{array}{l}\text { RA } \\
\text { SA }\end{array}$ & $\begin{array}{l}290.40 \pm 273.73 \\
376.82 \pm 483.98\end{array}$ & $\begin{array}{l}227.90 \pm 102.51 \\
352.69 \pm 397.54\end{array}$ & $\begin{array}{c}329.14 \pm 207.71 \$ \\
581.27 \pm 640.52\end{array}$ & $\begin{array}{c}\text { Time. } 057 \\
\text { Time } \times \text { Group.470 } \\
\text { Group. } 070\end{array}$ \\
\hline LF(ms2) & $\begin{array}{l}\text { RA } \\
\text { SA }\end{array}$ & $\begin{array}{l}124.39 \pm 100.54 \\
194.48 \pm 209.11\end{array}$ & $\begin{array}{l}130.12 \pm 102.79 \\
153.98 \pm 148.42\end{array}$ & $\begin{array}{c}155.93 \pm 101.73 \\
298.16 \pm 324.50 \$\end{array}$ & $\begin{array}{c}\text { Time.013* } \\
\text { Time } \times \text { Group.115 } \\
\text { Group.081 }\end{array}$ \\
\hline $\mathrm{HF}(\mathrm{ms} 2)$ & $\begin{array}{l}\text { RA } \\
\text { SA }\end{array}$ & $\begin{array}{c}59.12 \pm 52.72 \\
110.96 \pm 115.43\end{array}$ & $\begin{array}{c}75.93 \pm 62.28 \\
181.06 \pm 282.35\end{array}$ & $\begin{array}{c}60.25 \pm 51.49 \$ \\
177.12 \pm 243.92\end{array}$ & $\begin{array}{c}\text { Time. } 043^{*} \\
\text { Time } \times \text { Group.129 } \\
\text { Group.047* }\end{array}$ \\
\hline LFnu (\%) & $\begin{array}{l}\text { RA } \\
\text { SA }\end{array}$ & $\begin{array}{l}67.73 \pm 16.40 \\
62.65 \pm 21.28\end{array}$ & $\begin{array}{c}64.25 \pm 17.15 \\
54.05 \pm 19.13 \#\end{array}$ & $\begin{array}{l}72.93 \pm 15.41 \$ \\
64.56 \pm 16.37 \$\end{array}$ & $\begin{array}{c}\text { Time. } 001 * * \\
\text { Time } \times \text { Group.571 } \\
\text { Group.080 }\end{array}$ \\
\hline HFnu(\%) & $\begin{array}{l}\text { RA } \\
\text { SA }\end{array}$ & $\begin{array}{l}32.27 \pm 16.39 \\
37.35 \pm 21.28\end{array}$ & $\begin{array}{c}35.75 \pm 17.15 \\
45.95 \pm 19.13 \#\end{array}$ & $\begin{array}{l}27.07 \pm 15.41 \$ \\
35.44 \pm 16.37 \$\end{array}$ & $\begin{array}{c}\text { Time. } 001 * * \\
\text { Time } \times \text { Group. } 571 \\
\text { Group.080 }\end{array}$ \\
\hline $\mathrm{LF} / \mathrm{HF}$ & $\begin{array}{l}\text { RA } \\
\text { SA }\end{array}$ & $\begin{array}{l}3.79 \pm 4.84 \\
3.35 \pm 4.19\end{array}$ & $\begin{array}{l}3.22 \pm 4.29 \\
1.63 \pm 1.25\end{array}$ & $\begin{array}{l}4.77 \pm 6.09 \\
2.54 \pm 1.86\end{array}$ & $\begin{array}{c}\text { Time. } 018^{*} \\
\text { Time } \times \text { Group.155 } \\
\text { Group.199 }\end{array}$ \\
\hline
\end{tabular}

Values are mean \pm standard deviation

\#: significantly different from before-treatment by paired t-test

$\$$ : significantly different from during-treatment by paired t-test

*: significant at $\mathrm{p}<0.05$ by repeated measure ANOVA

**: significant at $\mathrm{p}<0.01$ by repeated measure ANOVA

RA: real acupuncture

SA: sham acupuncture 
needed to be performed to demonstrate whether acupuncture needling has the effect on HRV or not. This study was designed and conducted for that reason.

Among all results of this study, 2 of them are most notable. One is that RMSSD, SDNN, TP, and $\mathrm{HF}$ of the 4 parameters differed significantly between groups. The other is that most of the parameters, except for VLF and RMSSD, showed significant differences between times (excluding the effect of group). The latter result may be caused by shortness of rest before the first HRV measurement: subjects couldn't reach a stable ANS status. Although there is no golden standard for resting period, 5 minutes of rest may be insufficient compared to other studies. A study about the effect of electroacupuncture on the electroencephalogram (EEG) and HRV ${ }^{23)}$ set 30 minutes of resting before the measurement. Enough rest could result in increase of parasympathetic activity expressed by HF increase and HR decrease, which can be seen in this study.

Two parameters of RMSSD and HF are commonly known to reflect parasympathetic activity ${ }^{16}$, and these parameters showed significant differences between groups. Observing the change patterns of RMSSD and HF (Fig.4), both parameters showed decreasing pattern in the RA group compared to the SA group. This decreasing pattern can be recognized by the fact that the gap between both groups in each measurement is getting bigger over time. A possible explanation of this acupuncture effect is relative activation of the sympathetic nervous system. Relative activation of the sympathetic nervous system induced by decrease of the parasympathetic nervous system may function as a defensive mechanism against fat deposition ${ }^{24)}$. Relative sympathetic activation is also seen in LF/HF ratio. Although not statistically significant, baseline measurement of LF/HF increased compared to after-treatment measurement in the RA group and decreased in the
SA group.

Both TP and SDNN, which represent overall ANS function (both sympathetic and parasympathetic function) ${ }^{16)}$, showed significant increase over time. Compared to SA, RA showed less increase over time. This means that RA resulted in significant decrease of TP and SDNN with removal of time effects. This effect is considered to be affected by previously mentioned deactivation of parasympathetic function.

Another explanation for the decrease of SDNN is related to sympathetic activity. This parameter is negatively influenced by the sympathetic compound of the $\mathrm{ANS}^{16)}$. Thus, possible increase of sympathetic function can be assumed due to decrease of SDNN. Acupuncture's direct influence on the sympathetic nervous system needs further well-controlled study.

This study had several limitations. First, this study was composed of only one treatment. More than 1 month of longitudinal effects by regular acupuncture treatments can generate improvements obesity-related parameters including BMI, weight, waist circumference, etc. whereby correlation between improvements of obesity and changes of HRV indices can be analyzed. Second, stricter control could have been done with sufficient time of rest, as mentioned before, or the use of paced breathing protocols ${ }^{25}$. Third, evaluation of other relevant variables such as visceral fat and stress could show more meaningful results. Last but not least, a bigger sample size would have brought stronger results.

\section{Conclusion}

For the purpose of studying effects of acupuncture on HRV in obese (BMI $>25 \mathrm{~kg} / \mathrm{m}^{2}$ ) subjects, a total of 46 obese women aged from 21 to 54 , BMI range from 25.1 to $39.3 \mathrm{~kg} / \mathrm{m}^{2}$ were recruited and randomized into both RA $(\mathrm{n}=23)$ and SA groups $(n=23)$. A total of 3 instances of HRV analysis were conducted before, during, and after treatment. 
Statistical significant differences between time and groups were analyzed using repeated measure ANOVA, and the results are shown below.

1. All parameters of time domain analysis and frequency domain analysis except for RMSSD and VLF showed significant differences between times.

2. Mean RR showed a significant level of interaction between time and group $(\mathrm{p}=0.035)$, but the rest of the parameters showed no significant interaction between time and group.

3. Between groups, time domain analysis of SDNN, RMSSD and frequency domain analysis of TP and $\mathrm{HF}$ showed significant differences.

This study suggests that not only RMSSD and $\mathrm{HF}$, known to reflect parasympathetic activity, but also TP and SDNN, known to reflect overall ANS function, showed significant differences between groups. RA showed deactivation of parasympathetic function and relative increase of sympathetic activity. Further studies are necessary to uncover the mechanisms of acupuncture in obesity treatment.

\section{References}

1. Stein PK, Kleiger RE. Insights from the study of heart rate variability. Annu Rev Med. 1999;50: 249-61.

2. Baek J, Park D, Kim I, Won JU, Hwang J, Roh J. Autonomic dysfunction of overweight combined with low muscle mass. Clin Auton Res. 2013; 23(6):325-31.

3. Bigger JT Jr, Fleiss JL, Rolnitzky LM, Steinman RC. Frequency domain measures of heart period variability to assess risk late after myocardial infarction. J Am Coll Cardiol. 1993;21(3):729-36.

4. Lee S, Lee MS, Choi JY, Lee SW, Jeong SY, Ernst E. Acupuncture and heart rate variability: a systematic review. Auton Neurosci. 2010;155 (1-2):5-13.

5. Anderson B, Nielsen A, McKee D, Jeffres A, Kligler B. Acupuncture and heart rate variability: a systems level approach to understanding mechanism. Explore (NY). 2012;8(2):99-106.

6. Peterson HR, Rothschild M, Weinberg CR, Fell $\mathrm{RD}$, McLeish KR, Pfeifer MA. Body fat and the activity of the autonomic nervous system. $\mathrm{N}$ Engl J Med. 1988;318(17):1077-83.

7. van Baak MA. The peripheral sympathetic nervous system in human obesity. Obes Rev. 2001;2(1):3-14.

8. Windham BG, Fumagalli S, Ble A, Sollers JJ, Thayer JF, Najjar SS, et al. The Relationship between Heart Rate Variability and Adiposity Differs for Central and Overall Adiposity. J Obes. 2012;2012:149516.

9. Karason K, Molgaard H, Wikstrand J, Sjostrom L. Heart rate variability in obesity and the effect of weight loss. Am J Cardiol. 1999;83(8):1242-7.

10. Cho SH, Lee JS, Thabane L, Lee J. Acupuncture for obesity: a systematic review and meta-analysis. Int J Obes (Lond). 2009; 33(2):183-96.

11. Shiraishi T, Onoe M, Kojima T, Sameshima Y, Kageyama T. Effects of auricular stimulation on feeding-related hypothalamic neuronal activity in normal and obese rats. Brain Res Bull. 1995;36(2):141-8.

12. Shiraishi T, Onoe M, Kojima TA, Kageyama T, Sawatsugawa S, Sakurai K, et al. Effects of bilateral auricular acupuncture stimulation on body weight in healthy volunteers and mildly obese patients. Exp Biol Med (Maywood). 2003;228(10):1201-7.

13. Mercuro G, Podda A, Pitzalis L, Zoncu S, Mascia M, Melis GB, et al. Evidence of a role of endogenous estrogen in the modulation of 
autonomic nervous system. Am J Cardiol. 2000;85(6):787-9.

14. WHO. WHO Standard Acupuncture Point Locations in the West Pacific Region. Geneva, Switzerland: WHO WPRO, 2008.

15. Park J, White A, Lee H, Ernst E. Development of a new sham needle. Acupunct Med. 1999; 17(2):110-2.

16. Task Force of the European Society of Cardiology and the North American Society of Pacing and Electrophysiology. Heart rate variability. Standards of measurement, physiological interpretation, and clinical use. Eur Heart J. 1996;17(3):354-81.

17. Czura CJ, Tracey KJ. Autonomic neural regulation of immunity. J Intern Med. 2005; 257(2):156-66.

18. Nonogaki K. Obesity: autonomic circuits versus feeding. Nat Med. 1999;5(7):742-3.

19. Chang CS, Ko CW, Lien HC, Chou MC. Effect of electroacupuncture on St. 36 (Zusanli) and LI. 10 (Shousanli) acupuncture points on heart rate variability. Am J Chin Med. 2010; 38(2):231-9.

20. Hsu CH, Hwang $\mathrm{KC}$, Chao $\mathrm{CL}$, Chang $\mathrm{HH}$, Chou P. Electroacupuncture in obese women: a randomized, controlled pilot study. J Womens
Health (Larchmt). 2005;14(5):434-40.

21. Lee MS, Hwan Kim J, Lim HJ, Shin BC. Effects of abdominal electroacupuncture on parameters related to obesity in obese women: a pilot study. Complement Ther Clin Pract. 2006;12(2):97-100.

22. Chien LW, Lin MH, Chung HY, Liu CF. Transcutaneous electrical stimulation of acupoints changes body composition and heart rate variability in postmenopausal women with obesity. Evid Based Complement Alternat Med. 2011;2011:862121.

23. Yoon DS, Hong SW, Lee YS. The Effect of Electroacupuncture at Sobu (HT8) on the EEG and HRV. Korean Journal of Acupuncture. 2013;30(4):305-18.

24. Molfino A, Fiorentini A, Tubani L, Martuscelli M, Rossi Fanelli F, Laviano A. Body mass index is related to autonomic nervous system activity as measured by heart rate variability. Eur J Clin Nutr. 2009;63(10):1263-5.

25. Nunan D, Sandercock GR, Brodie DA. A quantitative systematic review of normal values for short-term heart rate variability in healthy adults. Pacing Clin Electrophysiol. 2010;33(11): 1407-17. 